\title{
Dental Care Practices, Beliefs and Knowledge among Pediatric Patient's Caregivers; a Cross-Sectional Analysis at Dental Outpatient Clinics
}

\author{
Bashar Reyad Elmomani ${ }^{1, *}$, Reham Adel Hjazeen², Mohammad Abdhameed Qudah², Ali Shebli Otoom², and Khaled Hussam \\ Hadadeen ${ }^{2}$
}

${ }^{1}$ Senior Specialist, Queen Alia Military Hospital-Orthodontic Dental Department, Jordan

${ }^{2}$ Dental Corps of the Royal Medical Services, Amman, Jordan

*Corresponding author: Bashar Reyad El Momani, Senior Specialist, Queen Alia Military Hospital-Orthodontic Dental Department, Jordan, E-mail: drbasharmomani@icloud.com

Received: 31 Dec, 2019 | Accepted: 13 Jan, 2020 | Published: 24 Jan, 2020

Citation: El Momani BR, Hjazeen AD, Qudah MA, Otoom AS, Hadadeen KH (2020) Dental Care Practices, Beliefs and Knowledge among Pediatric Patient's Caregivers; a Cross-Sectional Analysis at Dental Outpatient Clinics. Int J Dent Oral Health 6(1): dx.doi.org/10.16966/2378-7090.314

Copyright: (c) 2020 El Momani BR. This is an open-access article distributed under the terms of the Creative Commons Attribution License, which permits unrestricted use, distribution, and reproduction in any medium, provided the original author and source are credited.

\begin{abstract}
Aim: This cross sectional survey was carried out to explore and identify attitudes and beliefs amongst pediatric patient caregivers at their first visit to (KHOP) dentistry public sector clinics in Amman-Jordan.

Materials and Methods: A total of 333 questionnaires were answered by caregivers of children aged 4-10 years at their primary first visit to the pediatric dentistry clinics; the study spanned for 6 months. Data were analyzed using descriptive and inferential tests with SPSS version 25.

Results: Majority of children (71\%) came as emergency visits. More than $60 \%$ of interviewed caregivers think they should start tooth brushing for their children after 5 years of age. Similarly, $57 \%$ of subjects assume use of secondary dental hygiene practices as mouth rinses as the main cleansing practice. Exploring caregiver's knowledge showed; more than half (52\%) think that caries happens for reasons not under their control, while $60 \%$ believe that oral health has no effect on any systemic health conditions.
\end{abstract}

Conclusion: The data suggests there is a need for oral health awareness programs and likely this need extends nationally. It is important to reach parents and caregivers early in the child's life but including school teachers and staff could also be beneficial to reinforce oral health messages as the children develop. Oral health practices need to be enhanced along with oral hygiene beliefs and knowledge.

Keywords: Oral health; Dental care; Oral hygiene; Dental beliefs and knowledge; Caregivers

\section{Introduction}

The mouth serves as a "window" to the rest of the body, providing an indicator of general health and a sign/symptom of a systemic disorder [1]. A healthy stomodeum enables not only nutrition for the human body, but also enhances social interaction and promotes self-esteem and confidence [2,3]. Dental caries continues to be a chronic childhood disease in many countries and it affects the quality of life of children in many ways [4]. Naturally, Infants and young children rely on parents and care givers to support their oral health. Indifference toward adequate oral hygiene practice in children is widely known as the leading source of; dental caries $[5,6]$, a predisposing factor to periodontal diseases $[7,8]$, deterioration of an individual's long term dental care in adulthood [9]. Educating young children for better oral hygiene practices starts from building the knowledge and dental awareness into their primary caregivers, parents and school supervisors; this will raise the young child's oral and dental appreciation and enhance their early care practices. These effective oral hygiene habits lead to long term maintenance of hard and soft oral tissues [10]; it also minimizes the burden on medical and dental care health providers on national scales.

Nevertheless, the prevalence of oral diseases has been increasing in the developing countries [10]. Also a recent study in relation to
6-12 years old school children showed that Oral disease is a significant public health problem in Jordan [11]. Another national study showed caries experience measured via DMFT to be between 4-5 for children below 15 years [12] in parallel, Ababneh KT, et al. [13] showed that the prevalence of periodontal disease is $76 \%$ for gingivitis, $2.2 \%$ for aggressive periodontitis, and $5.5 \%$ for chronic periodontitis, and these numbers are in higher percentages in comparison to industrial countries [14].

Jordan health system provides dental insurance coverage for a significant fraction of its 10 million relatively young population; public insurance serving almost 55\% of Jordanian families [15]. This alteration in demographics has also put a strain on the public dental services due to an existing need and increased demands. It is, therefore, important to explore the oral health knowledge and attitudes of parents and caregivers to minimize the burden of dental diseases for individuals, families, communities and national health care systems.

This cross sectional survey was carried out to explore and identify oral health attitudes and beliefs amongst pediatric patient caregivers at their first visit to (KHOP) dentistry public sector clinics in Jordan. Findings from this study have the potential to support future decisions as policy makers strive to address the problems of dental caries in Jordanian children. 


\section{Materials and Methods}

This cross sectional survey included a sample of children $(n=333)$ visiting the pediatric dentistry clinic for the first time, the study included all healthy non-syndromic or medically compromised children aged between 4-10 years accompanied by their primary caregiver/s, Only the primary caregivers were identified and recruited, children accompanied by other family member/relatives were excluded.

The prime investigation was: What are the oral health beliefs and attitudes caregivers of children visiting the outpatient's public dental clinic for the first time?

The study had the ethical approval of the Royal Medical Services (RMS) profession's ethics committee 3/2019., and all subjects signed a consent form to participate in this short survey. Later, an attending calibrated pediatric dentist (R.H) had a 10-minuteslength interview at the dental office to fill out a standardized short survey form (Figure 1).

The interview gathered epidemiological data including: information about gender, number of siblings, residence. While a 5 items selfmade questionnaire explored the reason for visit and the dental care practices, beliefs, and knowledge among children's caregivers.

Questionnaire was constructed by first author dr. B.M based on readings of relevant clinical research literature, one consultant orthodontist and pediatric dentist revised the questionnaire.

The study spanned for six months at (RMS) outpatient pediatric clinics, March-September 2019.

The primary study question; why you visit us today? Answers were divided to: for an emergency, a referral or for dental check-up.

\section{Patient name:}

National \#:

Military \#:
Age:

Residence:

Siblings' \#:

4-10 years old pediatrics patients and their parents interviewed at first visit only...

Reason of visit:

\section{- Emergency}

- Referral

\section{- Check-up}

\section{Questionnaire:}

1) When you think a child should start teeth brushing?

- 2-3years

- 5-6years

- 8-9years

- >12years

2) Which is the most important for oral care?

- Mouth wash

- $\quad$ Teeth brushing

- Toothpaste

3) Does oral health affect general health status?

Yes/No

4) Why you think caries occur?

Food type not enough care genetics they happen no matter what

5) Do you think maintaining a primary tooth or molar is very important for the successors?

\section{Yes/No}

Figure 1: The questionnaire used in this cross-sectional analysis. 
Other questions answers were based on multiple choices or using yes/no, no open ended answers were allowed in this questionnaire (Figure 1).

Subjects responses were later transferred and categorized using Microsoft excel and results analyzed using the SPSS version 25 statistics software, simple percentage ratio calculations were employed.

\section{Results}

We conducted the survey for $n=333$ pediatric patients; 161 male and 172 female children aged between 4-10 years accompanied with their primary caregivers; 327 were biological parent/s, others were legal guardians.

About two-thirds of children resided in the suburbs of the capital and majority of children $80 \%$ had more than 3 siblings. Most children visited the dental clinic for their first time for emergency reasons (71\%) which were related to dental pain or trauma, a few were referred from general or specialist dentists (19\%) and 10\% came to check-up their children dentition (Figure 2).

Caregiver's beliefs and knowledge were assessed with three questions, the first was: When should a child's regular tooth brushing start? $60 \%$ of caregivers believe it should start at 5-6 years of age, $25 \%$ said it can begin at 8-9 years of age, and only $15 \%$ knew that tooth brushing should begin as early as teeth begin to erupt in their child's oral cavity at 2-3 years of age. Second question was: what do you think causes tooth decay? About the half (49\%) attributed this to reasons beyond the caregivers control and caries happen no matter what, while $23 \%$ say it's due to genetics, $20 \%$ believed that the ineffective dental care methods lead to tooth caries. Finally, $8 \%$ think that the food type may cause tooth decay for their children (Figure 3).

The third question assessed parent's beliefs and knowledge concerning the relationship between oral and general health with $60 \%$ of parents believing that oral health has no effect on systemic conditions.
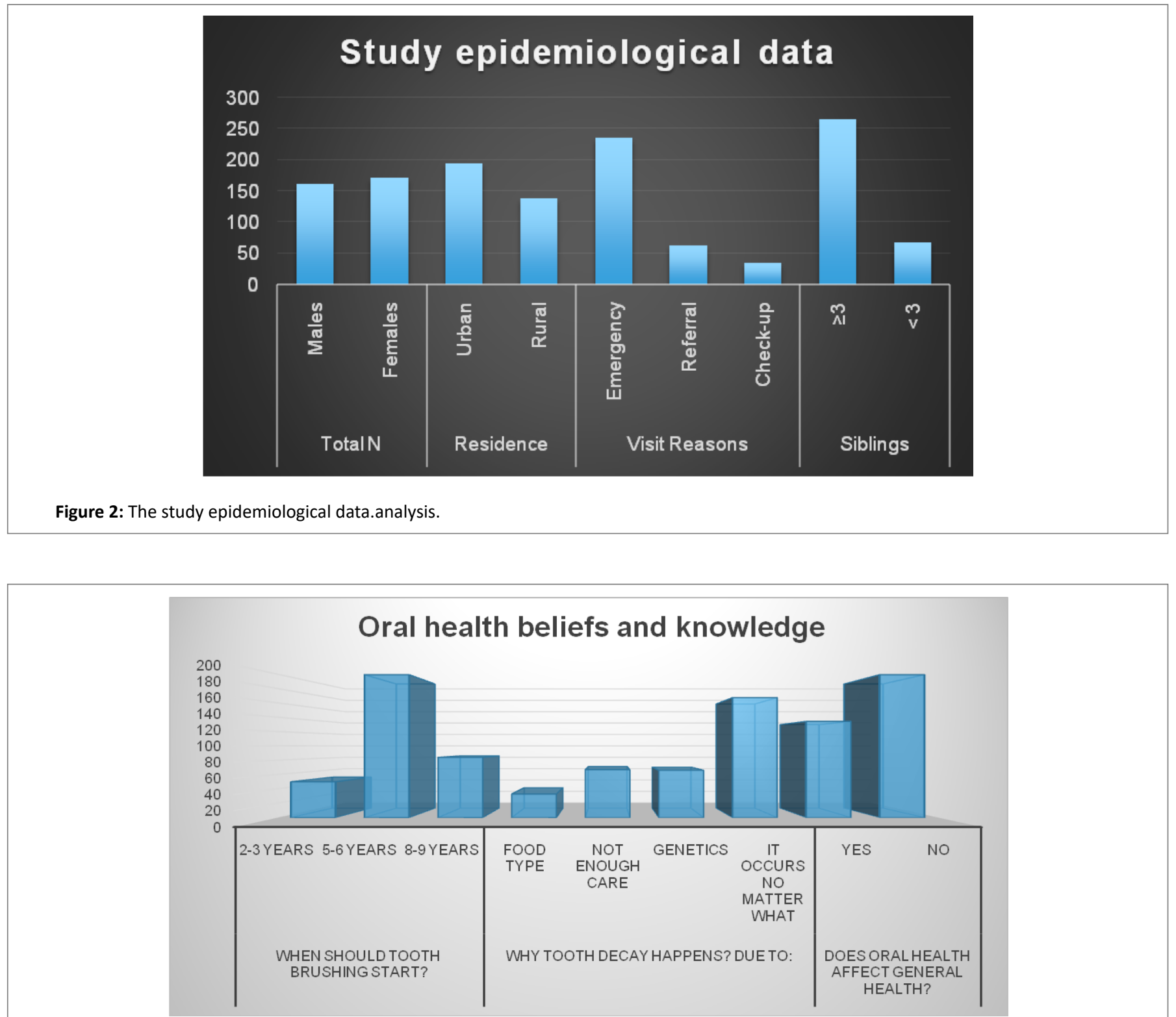

Figure 3: Oral health beliefs and knowledge. 
Concerning oral hygiene practices, 57\% thought that rinsing with a mouth wash is sufficient for cleaning teeth, less than $30 \%$ chose teeth brushing as the best method, and the remaining 15\% thought that the type of toothpaste affected cleaning outcomes (Table 1). When parents were asked whether maintenance of a primary tooth was important for later growth; the majority (67\%) believed that maintaining a primary tooth isn't that important for the eruption of their permanent successors.

\section{Discussion}

We attempted to explore a sample of Jordanian family's caregivers, we believe that their perceived dental knowledge and beliefs would mirror on their primary dependents their beloved children, and this will affect the actions in use toward oral hygiene habits and dental care practices positively or negatively. Further, these healthy oral habits and practices if introduced early into a child's life would promise a long term oral health and dental care for the individual and his/her future offspring's. Insufficient knowledge for caregivers and/or parents is among the main factors behind dental diseases and ineffective oral hygiene practices and declining general health status [16,17].

This study deliberately explored the first clinic visit; why do parents take their children to the dental service? Sadly, this survey found that more than $70 \%$ of first time visitors coming for emergency reasons, not for check-ups or regular pediatric dental care. This might indicate that parents and caregivers didn't sufficiently integrate the oral health messages such as the need for regular check-ups and the need to initiate oral health care upon the eruption of the first tooth.

The findings from this study are similar to a study conducted by Jain $\mathrm{N}$, et al. [18] in which $54 \%$ of study population attended a dental visit only when that were in pain.

While evaluating oral awareness and beliefs, about $60 \%$ of children's primary caregivers believed that oral health has no major effect on the general health; this is supported by a global survey [19] undertaken fifteen years ago. However, Kapoor D, et al. [20] found that $43 \%$ of his study participants knew any significant relation exists between oral health and systemic health; this finding underestimates the possible impact of oral conditions on systemic health given that the possible relationships are complex and multiple [21].

Furthermore, incorrect perceptions and beliefs might largely affect a child dental health for both the short and long terms; as most parents think that regular tooth brushing should start after 5-6 years of age not before! Only $15 \%$ knew that teeth brushing must begin as early as teeth begin to erupt in their child's oral cavity at 2-3 years of age. No national or regional study was found that assessed this knowledge of parents.

Basic dental awareness issues such as tooth decay were also at a low level. More than half of the respondents suggested that caries was beyond parents' control with $20 \%$ relating caries to genetics and less than $30 \%$ knew that diet and ineffective oral hygiene lead to tooth decay.

Some studies $[22,23]$ under taken with primary care providers also show that as high as $61 \%$ of subjects only visit a dentist for extractions or emergencies. Interestingly, Singh A, et al. [24] showed that most

Table 1: Dental care practices.

\begin{tabular}{|l|l|l|}
\hline \multicolumn{3}{|c|}{ The most important for dental care is } \\
\hline Mouth wash & Toothpaste & Toothbrush \\
\hline $\mathrm{n}=189(57 \%)$ & $\mathrm{n}=44(13 \%)$ & $\mathrm{n}=100(30 \%)$ \\
\hline
\end{tabular}

parents in India do not understand that it is important to teach and guide their children in oral health strategies.

The third part of this survey explored oral health practices; 57\% of parents thought that rinsing with a mouth wash was enough for cleaning teeth, while $15 \%$ think that the type of toothpaste to be the most important aspect of biofilm removal. Only less than 30\% chose tooth brushing as the best method. Similar studies conducted in Saudi Arabia and India $[20,21]$ found that only $25 \%$ of studied groups brush their teeth twice a day and the use of dental aids such as dental floss is rather limited, whereas in a United States based study [22] 90\% of participants brush their teeth at least twice daily. This shows large discrepancies in healthy practices between Jordan and the United States or may be developing and developed countries; and this has implications for the oral health status of Jordanian children and their quality of life, it also has implications for the 'dental service' in Jordan and its current programming.

We think providing a free public dental service-without taking into consideration the ratio of patients to health providers, lack of audit and unclear jobs description-this may reflect some challenges within the 'dental service' with regard to roles, monitoring and funding.

Over the past two decades developing countries have shown increasing level of tooth decay and a positive correlation of low awareness, oral disorders and in effective oral health practices [23]. Which significantly affect a person's oral self-care? This short survey is a reflection of a gap in oral health services. There appears to be a need for an increased focus on oral health promotion including education.

One limitation of this short survey, the Epidemiological data gathered showed most families living in the suburbs of the capital Amman, and most families selected have more than three children, again developing countries overall have an increasing younger population and this places strain on dental services, we think this study didn't gather enough epidemiological data to make any assumption in this field [24-27].

\section{Conclusion}

This survey suggests that dental care practices, beliefs and knowledge among pediatric patients care givers are defective and sometimes faulty. This requires adoption of new innovative and effective means at public sectors to enhance knowledge and consequently oral hygiene practices.

\section{References}

1. Stanfield CL (2017) Principles of Human Physiology. $6^{\text {th }}$ Edition, Pearson.

2. Kamran A, Bakhteyar K, Heydari H, Lotfi A, Heydari Z (2014) Survey of oral hygiene behaviors, knowledge and attitude among school children: A cross-sectional study from Iran. Int J health Sci 2: 83-95.

3. Gundala R, Chava VK (2010) Effect of lifestyle, education and socioeconomic status on periodontal health. Contemp Clin Dent 1: 23-26.

4. Benzian H, Williams D (2015) The challenge of oral diseases-A call for global action. The oral health atlas, $2^{\text {nd }}$ Edition, FDI World Dental Federation.

5. Towards a cavity-free future. King's College London Dental Institute, England.

6. Suprabha BS, Rao A, Shenoy R, Khanal S (2013) Utility of knowledge, attitude, and practice survey, and prevalence of dental caries among 11- to 13-year-old children in an urban community in India. Glob health action 6: 20750. 
7. Nazir MA (2017) Prevalence of periodontal disease, its association with systemic diseases and prevention. Int J Health Sci (Qassim) 11: 72-80.

8. Jain N, Mitra D, Ashok KP, Dundappa J, Soni S, et al. (2012) Oral hygiene-awareness and practice among patients attending OPD at Vyas dental college and hospital, Jodhpur. J Indian Soc Periodontal 16: $524-528$

9. Cohen LC, Dahlen G, Escobar A, Fejerskov O, Johnson NW, et al. (2017) Dentistry in crisis: time to change. La Cascada Declaration. Aust Dent J 62: 258-260.

10. Peres MA, Macpherson LMD, Weyant RJ, Daly B, Venturelli R, et al. (2019) Oral diseases: a global public health challenge. Lancet 394 249-260.

11. Rajab LD, Petersen PE, Baqain Z, Bakaeen G (2014) Oral Health Status Among 6- and 12-year-old Jordanian Schoolchildren. Oral Health Prev Dent 12: 99-107.

12. Taani DS (2004) Oral health in Jordan. Int Dent J 54: 395-400.

13. Ababneh KT, Hwaij ZMFA, Khader YS (2012) Prevalence and risk indicators of gingivitis and periodontitis in a multi-centre study in North Jordan: A cross sectional study. BMC Oral Health 12: 1.

14. Watt RG, Daly B, Allison P, Macpherson LMD, Venturelli R, et al. (2019) Ending the neglect of global oral health: time for radical action. Lancet 394: 261-272.

15. Al Nsour M, Iblan I, Tarawneh MR (2018) Jordan Field Epidemiology Training Program: Critical Role in National and Regional Capacity Building. JMIR Med Educ 4: e12.

16. Hedman E, Ringberg K, Gabre P (2009) Oral health education for schoolchildren: a qualitative study of dental care professionals' view of knowledge and learning. Int J Dent Hyg 7: 204-211.

17. Mathur A, Gupta T (2011) Oral health attitude knowledge behavior and consent towards dental treatment among school children. J Orofac Res 1: 6-10.
18. Jain N, Mitra D, Ashok KP, Dundappa J, Soni S, et al. (2012) Oral hygiene-awareness and practice among patients attending OPD at Vyas dental college and hospital, Jodhpur. J Indian Soc Periodontal 16: 524-528.

19. Petersen $\mathrm{PE}$, Bourgeois D, Ogawa H, Estupinan-Day $\mathrm{S}$, Ndiaye $\mathrm{C}$ (2005) The global burden of oral diseases and risks to oral health. Bull World Health Organ 83: 661-669.

20. Kapoor D, Gill S, Singh A, Kuar I, Kapoor P (2014) Oral hygiene awareness and practice amongst patients visiting the department of periondontology at a dental college and hospital in north India. Indian J Dent 5: 64-68.

21. Ziebolz D, Jahn C, Pegel J, Semper-Pinnecke E, Mausberg RF, et al. (2018) Periodontal bacteria DNA findings in human cardiac tissueis there a link of periodontitis to heart valve disease? Int J Cardiol 251: 74-79.

22. Al-Omiri MK, Al-Wahadni AM, Saeed KN (2006) Oral health attitudes, knowledge and behavior among school children in North Jordan. J Den Educ 70: 179-187.

23. Sharifirad G, Entezari MS, Kamran A, Azadbakht L (2009) The effectiveness of nutritional education on the knowledge of diabetic patients using the health belief model. Res Med Res 14: 1-6.

24. Singh A, Gambhir RS, Singh S, Kapoor V, Singh J (2014) Oral health: how much do you know? - A study on knowledge, attitude and practice of patients visiting a north Indian dental school. Eur J Dent 8: 63-67.

25. Janjoom HM (2001) Preventive oral health knowledge and practice in Jeddah, Saudi Arabia. JKAU Med Sci 9: 17-25.

26. Diwan S, Saxena V, Bansal S, Kandpal SD, Gupta N (2011) Oral Health: Knowledge and Practices in Rural Community. Indian J Comm Health 22: 29-33.

27. Oliveira ER, Narendran S, Williamson D (2000) Oral health knowledge, attitudes and preventive practices of third grade school children. Pediatr dent 22: 395-400. 